POLLACK PERIODICA

An International Journal for Engineering and Information Sciences

DOI: $10.1556 / 606.2018 .13 .1 .16$

Vol. 13, No. 1, pp. 181-192 (2018)

www.akademiai.com

\title{
EXPLORING THE URBAN AND SPATIAL PORTRAIT OF KOSOVO THROUGH THE CONCEPTS OF 'NETWORKS, BORDERS AND DIFFERENCES'
}

\author{
${ }^{1}$ Dukagjin HASIMJA, ${ }^{2}$ Teuta JASHARI-KAJTAZI \\ ${ }^{1,2}$ Department of Architecture, Faculty of Civil Engineering and Architecture \\ University of Prishtina, Bregu i Diellit p.n, Prishtina, Kosovo \\ e-mail: ${ }^{1}$ dukagjin.hasimja@uni-pr.edu, ${ }^{2}$ teuta.kajtazi@uni-pr.edu
}

Received 29 September 2017; accepted 27 October 2017

\begin{abstract}
To understand Kosovo today, its urbanization trends and forms, it is necessary to know the historical geography of this territory and the state of art of remnants that shape its cultural (urban/rural) and natural landscape. Mapping and interpreting of these places opens the opportunity to understand the transitional nature of Kosovo's urban reality today, and to inspire the comprehension of its future development within the European context. This will reveal the temporal and spatial consistency of Kosovo's urban form and its consolidated geography. This logically leads to a brief history of the territory and a better understanding of modern-day Kosovo's urban and spatial planning and future endeavors in the same context leading at the same time towards the processes of regional interaction or heterogeneity.
\end{abstract}

Keywords: Spatial planning, Urban portrait, Urban history, City networks, City planning

\section{Introduction}

Since 1999, Kosovo is faced with a complex transition in all spheres of life. One of the most pressing challenges of the first decade was the reconstruction of the country. Although the process of reconstruction was substantially supported by the international community and funds, the overall result in the development of the territory (settlements, basic infrastructure, institutions, etc.) was far from being satisfactory when comparing to other regional countries that used to be part of the former Yugoslavia. The reason for this relies in the fact that Kosovo has been the less developed part of region during the previous regime; hence, the reconstruction efforts after 1999 could have not addressed 
the very pressing development issues, which portrayed Kosovo's history in the twentieth century.

Today, the problem of unfinished urbanization remains the greatest challenge for Kosovo. As of 2010 - respectively, the second decade of transition - the focus has shifted to a long-term and sustainable development. In 2010 the Spatial Plan of Kosovo was adopted, and legal and institutional framework on spatial development is almost completed. However, understanding of the physical reality of cities and landscapes in this contemporary context remains utterly conventional in Kosovo. In this endeavor, Kosovo-Urban Portrait [1, p. 193] is indented to add value to the Spatial Plan of Kosovo by introducing topics of research in the form of open questions and possible scenarios for Kosovo's future development, and by that, of its integration in the regional spatial processes, and beyond.

\subsection{Urban portrait and urban history of Kosovo}

Historically, Kosovo was a territory being caught in the crossroads of various influences. Since the antiquity, many battles have been fought in this territory; borders were drawn on it or have crossed it. Borders have often divided the present-day territory of Kosovo according to interests and needs of empires. These circumstances have shaped Kosovo's profile as a 'marginal place of meeting of different cultures, traditions and state arrangements' [2, p. 124]. At the same time, throughout the history Kosovo has maintained its centrality in the region. There are seven historic layers that support the argumentation given above:

Prehistory, characteristic for the networked settlements (6500 BC to $1 A D$ ) - that is, consolidated micro regions, which in spatial terms relate quite closely to the regional division as presented in the Spatial Plan of Kosovo. It is worth mentioning that with the spread of agriculture, according to the sources, the beginnings of $5000 \mathrm{BC}$ were the period of population explosion in the Balkan, which resulted in densely populated villages. The regions of Prishtina and Mitrovica, and partially the region of Ferizaj, although they comprise consolidated micro regions, may be regarded as a sub-region of early Neolithic sites as opposed to the rest of Kosovo, respectively, Prizren, Gjakova and Peja, the identification stamp of which are Metal Age forts and burial mounds (Illyrian tumulus) (Fig. 1).

Roman settlements and roman itineraries (1st to 4th century AD) - which today is best realized through archeological sites known as roman settlements of various functions and sizes, as an example of Scupi, Ulpiana, Naissus, Municipium Dardanorum, etc, researched since the second part of the 19th century. These settlements were apparently well connected in the regional terms, given the fact that two major roman roads used to cross through ancient Kosovo territory and constituted the main traffic network in this region (Fig. 2), not only during Antiquity, but also later during the Middle Ages. Today, it is noted that the remnants of major Roman settlements (archeological sites) in Kosovo are represented through spatial axis, with the exception of the Peja/Gjakova Region, which is a more concentrated and micronetworked region, and can connect to the rest of axis through landscape approach and design considerations. 


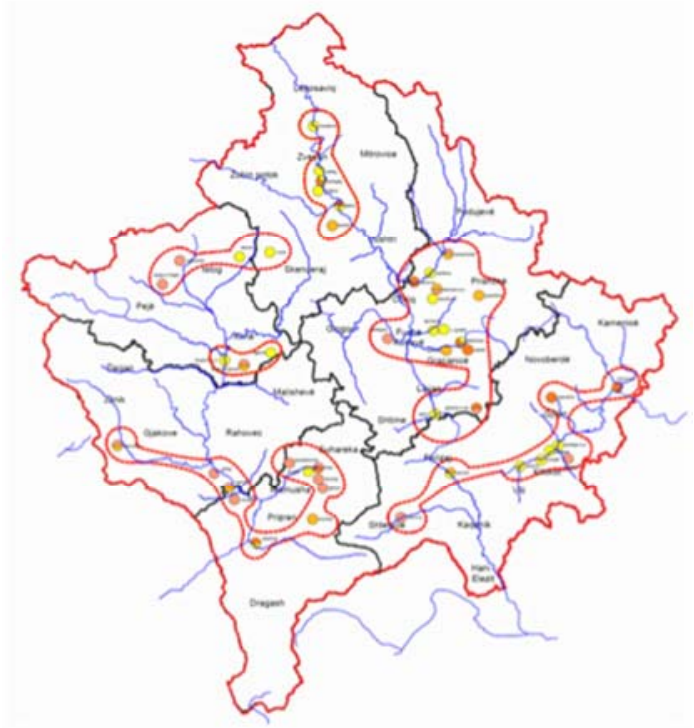

Fig. 1. Major prehistoric archeological sites, (Source: Authors plot, D. Hasimja, T. Jashari-Kajtazi)

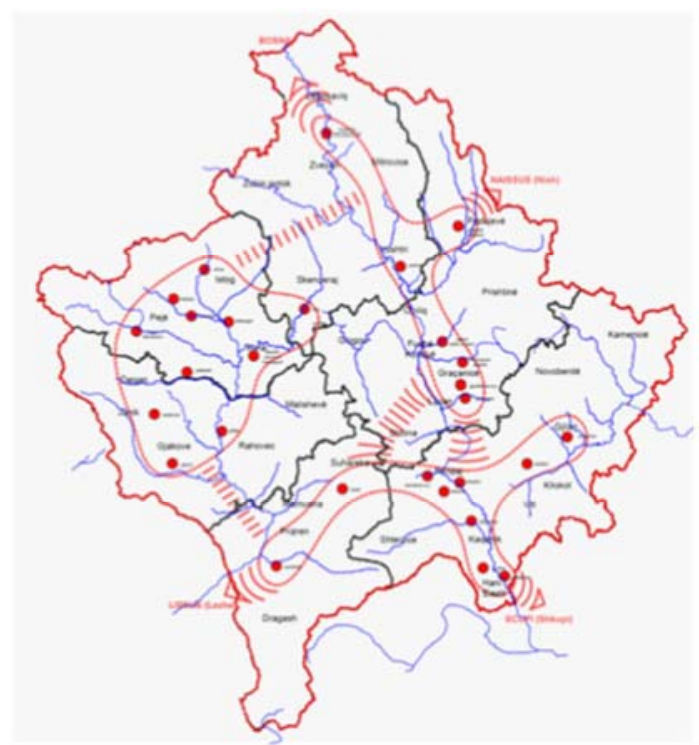

Fig. 2. Roman Settlements and itineraries (Source: Authors plot, D. Hasimja, T. Jashari-Kajtazi)

Late antiquity and early Byzantium: fortified settlements and the paleo Christian church architecture (4th to 6th AD) - During this period, the present day territory of 
Kosovo was part of the Kingdom of Dardania (later the Roman Province of Dardania) which, based on archaeological documentation, and relevant supplementary data in scientific disciplines, used to be characterized by a very advanced civilization, which reflected quite a cosmopolite development in the age of Antiquity [3, pp. 77-78]. Characteristic for this period is the presence of a variety of fortified settlements set in high hills, with strategic geopolitical positions out-looking mines and fertile lands - a layer, which is still visible and may be fostered in the future (Fig. 3).

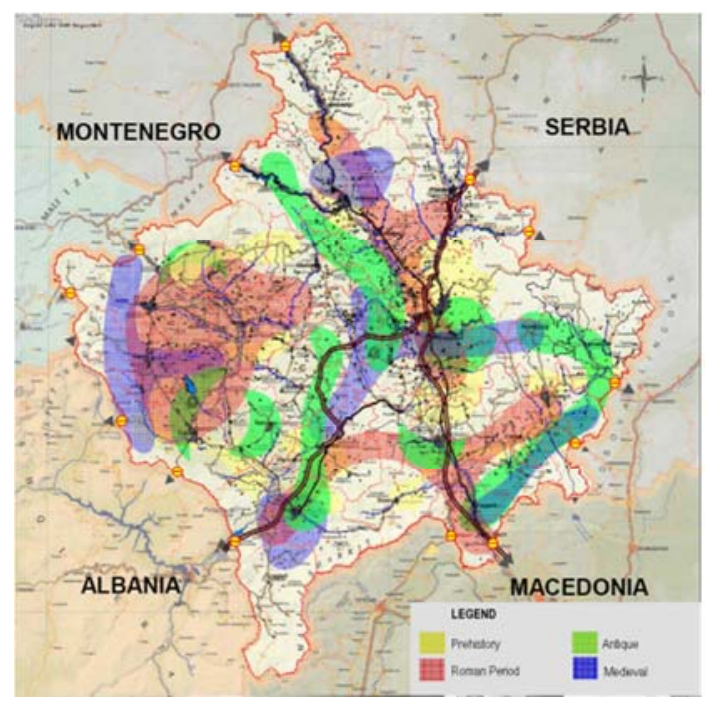

Fig. 3. Cultural landscapes of Kosovo. Extrapolation of cultural layers by historic periods, (Source: Authors plot, D. Hasimja, T. Jashari-Kajtazi)

Middle ages: fortified settlements and Orthodox Church architecture (6th to 14th $A D)$ - After the partition of the Roman Empire, the territory of modern-day Kosovo was situated in its eastern part, later known as Byzantium; ruled by Bulgaria Between around 850 until 1216, when Stephen the First - Crowned, the son of the Serbian King Nemanja, finally conquered the whole territory of Kosovo. Further expansion of Serbian despotism in the south removed the territory of Kosovo from the bordering line with Byzantium [2, p. 22]. Beside the marvelous medieval churches built during the middle ages, examples of Patriarchate of Peja, The Decan Monastery, The Gracanica Monastery, and the Church of Leviska or St. Friday's Church in Prizren, traces of medieval settlements and forts have also survived the time and most of them are likewise protected by law. The Prizren castle and some other fortified settlements (Vërboc- Drenas, Pogragjë-Gjilan, etc), which date back to Antiquity, were used in continuity throughout the Middle Ages. Today, this layer, which indicates a ring of settlements, is also visible in spatial terms.

Ottoman period: Consolidation of the city form (14th to early 20th century) - During the five centuries of the Ottoman era, settlements in Kosovo developed gradually in the spirit of an urban culture, which apart from religious buildings brought a variety of 
public facilities; the most representative urban intervention during the ottoman era is the public market, or Bazaar. Apart of defining the urban economic profile, Bazaar also defined the socio-political core of towns. In general, urban centers developed their local features depending on the natural resources and the economic profile inherited from the middle ages, yet, their townscape and public functions developed according to the Empire's politics for consolidation of its economic force. In this respect, major towns in Kosovo can be divided into the main typologies:

a) mining towns;

b) administrative and socio-economic centers; and

c) active trade and crafts' towns.

Socialist Modernization: Fragmented Urbanization and the Survival of the traditional (1945-1999) - One of the goals of the former socialist Yugoslav policies for urban planning was to diminish the differences between rural and urban lifestyles [4], for Kosovo this meant complete transformation of the oriental type of city (Fig. 4).

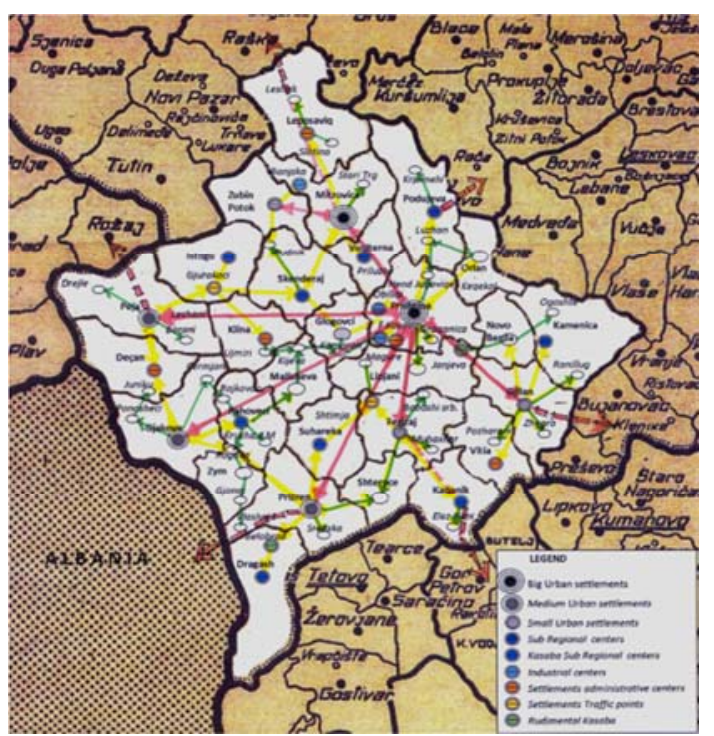

Fig. 4. Types of urban settlements in Kosovo in 1970s, (Source: Authors plot, D. Hasimja, T. Jashari-Kajtazi)

Yet, the envisioned transformation into modern towns was only implemented in parts and not as a whole; in this fragmented approach to urbanization almost all towns lost their historic characteristics, some more and some less. While Prishtina and the rest of cities, which used to comprise the so-called administrative and mining region during the ottoman times were transformed to an unprecedented scale; former active trade centers in the Dukagjini Valley- Prizren, Peja and Gjakova, retained in a larger extend their inherited urban feature [5], with central part of much interest being the old Bazaars. An important task of the former Yugoslav planning for Kosovo in specific was the creation 
of agricultural settlements and centers for industrial processing. In due course, three types of settlements were shaped:

- Large urban settlements, that is regional centers/cities (Prishtina 69.524 and Mitrovica 42. 241 habitants);

- Middle urban settlements-cities (Prizren, Gjakova 29.638 and Peja 42.113 habitants); and

- Small urban settlements (Ferizaj 22.372 and Gjilan 21.271 habitants).

- Prishtina as a capital got certain concentrated functions usually tertiary and quartier [6, p. 84].

Post-conflict transition (from 1999 onwards) - Since the termination of the conflict in 1999, Kosovo is faced with a complex transition in all spheres of life. One of the most pressing challenges of the first post-conflict decade was the reconstruction of the country. The analysis to follow will in more details elaborate the characteristics of modern-day Kosovo urban and spatial development.

\section{Kosovo presented in terms of networks, borders and differences}

Despite the fact that the general goal of the modern-day Kosovo is country's overall development in line with European development and global trends, the specific urban character of Kosovo remains poorly explored. In this process, the most pressing challenge lies in the comprehension and in the effective use of networks of cities for the purpose of economic and social development. Not only the network of cities within the borders of Kosovo, but also beyond, in a regional context. This would mean to explore differences encountered in the demographic, economic, and spatial nature of Kosovo, which has challenged a diverse imposition and the use of borders in territorial, social, economic, political and cultural terms. Therefore, urban portrait of Kosovo should address those fundamental components that link people with the settlements they live, through provision of different patterns which highlight the diversity of Kosovo's cultural and natural settings and the potential for regional networking, which needs to be validated and promoted in the future.

\subsection{Networks}

Networks are spaces of exchange and communications. Their physical reflection is that of an abstract and contractual network which is used by 'exchangers' and 'communicators' of products and information, within and between spaces they connect [7, p. 266]. The physical space, which according to Lefebvre is the 'initial basis or foundation of social space' [7, p. 402], is networked through physical infrastructure, which connects diverse places and which concurrently ends their isolation [7, p. 378].

Settlements, and thus cities, represent a form of a network which differentiates depending on the range, intensity and the complexity of cities' nature of urbanization (Fig. 5). Interaction among these three properties is in fact what provides information about the density of cities and what in fact shapes the physiognomy of Kosovo cities in particular [1, p. 42]. There are 1457 settlements in Kosovo, of which 38 are of a 
municipal level, and the rest are villages [8, p. 30]. In general, the trend of the settlement structure in Kosovo after 1999 is vastly determined by concentration of population in the more developed urban areas, while mountainous and border areas being characterized by poor social infrastructure and other sector development are being challenged by depopulation. However, settlements in Kosovo have great potential to create a sustainable network, regardless of the topographic constrains, but the challenge remains economic stability and the infrastructure in mountainous and bordering settlements.

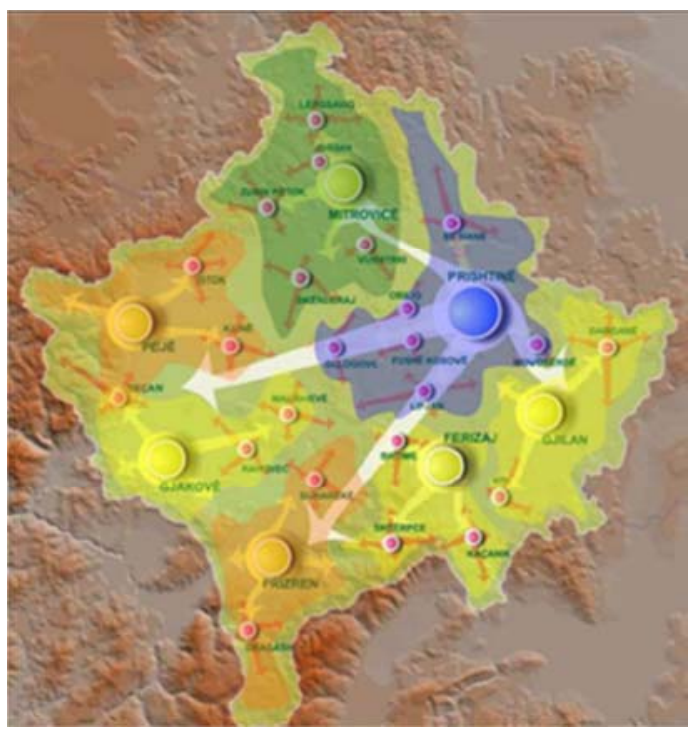

Fig. 5. The network of urban centers in Kosovo and their development directions (Source: Institute for Spatial Planning, KS)

On the other hand, the network of physical infrastructure has been part of Kosovo's national agenda in the last few years, with network of basic infrastructure (streets and telecommunication) being perceived as potential generators of economic growth. The last 5 years, huge efforts were made by the Government to connect the most remote settlements in Kosovo: Skenderaj, Drenas, Malisheva, Kacanik and Shtime, including the connection of Kosovo with Albania through a modern highway.

\subsection{Borders}

Although the borders are not considered primarily as an urban phenomenon [1, p. 50], the 'border' and the 'edge' have become the prevalent metaphors for the city [9, p. 4]. Nowadays the used phrases are: border cultures, borderlands, edge cities, etc, used by planners, architects, anthropologists, theorists, etc, in their attempts to explain the 'dissolution of the traditional limits and lines of demarcation due to rapid urbanization and globalization' $[9, \mathrm{p} .4]$. In the process in which the city absorbs borders of the formerly autonomous rural settlements, the lines of demarcation, that is 
borders or edges, are transformed into a zone of exchange. Study finds that cultural and natural landscape should be considered in exploiting the borders of urban dynamics in Kosovo and in its future direction, given the fact that, as promoted by the EU, starting the administrative boundaries of cities, any more do not indicate the physical, social, economic, cultural or even environmental actuality of urban and spatial development, expressing the need for new forms of flexible governance [10, p. vi].

\subsection{Differences}

In the Urban Border Bi-City Biennale of Urbanism $\backslash$ Architecture held in 2013 in Shenzhen, it was recognized that what dominates the cities throughout the world is a kind of generic similarity, while urban diversity, differences, specificities and individuality are more often hidden or disregarded (Fig. 6). It is the very differences and specificities that define the magnitude of heterotopy in urban spaces, thus contributing to multilayered urban dynamics. Drawing from this, the challenge ahead is to accept fragmentations and differences that derive from the dynamics of urban development, while seeking the potentials and possibilities to bridge and profile these differences.

In the case of Kosovo, this would mean to work towards: alleviating the unequal economic development rate, which has led to depopulation of the underdeveloped settlements, resulting in majority in migration from rural to urban areas, much more than from urban to more developed urban areas, and alleviating the differences in territorial development (urban patterns) between urban and rural.

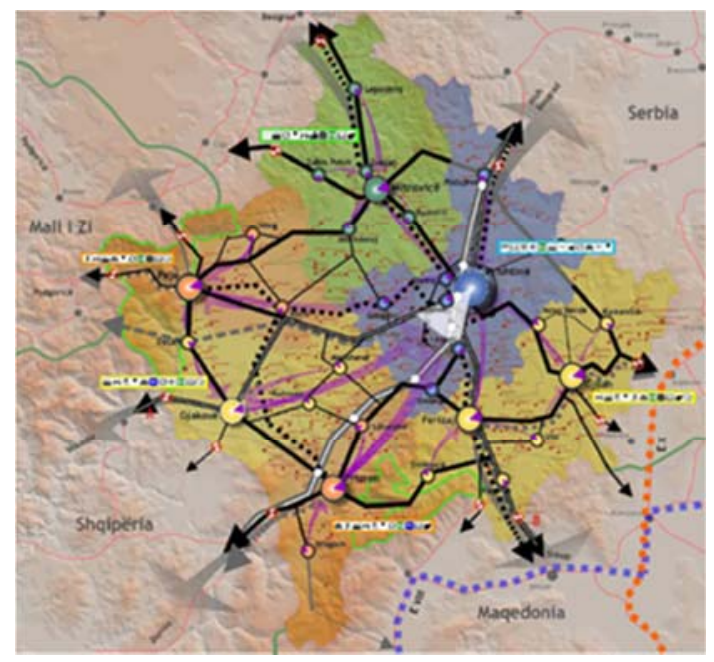

Fig. 6. Strategy of spatial development according to the Spatial Plan of Kosovo (Source: Institute for Spatial Planning, KS)

\subsection{Networks, borders, differences}

It should be acknowledged that a New Understanding of the urban and spatial planning takes account of productive differences in the realm of networks, which 
overcome territorial border realities, as new ways to analyze and manage the urban reality today. Hence, it is the criteria of networks, borders, and differences, that is to say, the quality of dynamic and processes of interaction, and not the size, density, or heterogeneity makes a city today.

\section{Potential for cross-border cooperation: linking Albania, Kosovo and Macedonia}

Kosovo's urban portrait cannot be understood outside the context of the Western Balkans and its future integration in the European socio-political, cultural and economic agenda. The future integration of Western Balkans' into European Union, calls for strategic orientation and adaptation of processes to meet the requirements that spring from the integration process. Kosovo as a geographic, natural and cultural unit belongs to the European continent; the question that remains almost unaddressed in the Kosovo context is the revealing of solid basis for its future integration strategies in the domain of spatial integration. In order to address this issue, it is important to investigate components of the Kosovo urban profile that insert the most profound characteristics of the country's spatial potentials. The study suggests that the contemporary Kosovo can build its future urban portrait based on its resources only if viewed within the framework of networked socio-spatial spaces, as opposed to fragmented territories enclosed by boundaries of cultural, economic, and political character [11, p. 194].

Drawing from the abovementioned, the study suggests that this diversity, that is, Kosovo's rich cultural and natural resources, should be used for devising a different approach in urbanism that bridges territories and people, in which case, borders are diminished while the differences, that is diversity, strengthens.

This task would move ahead through introduction of typologies, which insert the most profound qualities of socio-spatial spaces and can become the platform for future development of Kosovo's urban profile that guarantees its sustainable development and representation in Europe:

- Metropolitan Capital (Prishtina);

- Network of cities; and

- Regional cooperation, under which shall be promoted: natural landscape regions, cultural landscape regions, and cross-border cooperation.

\subsection{Metropolitan Capital (Prishtina)}

Metropolitan Capital Prishtina is a concept that has already been promoted by the Municipality of Prishtina. However, the Spatial Plan of Kosovo, which transmits the stance of the central governance, envisages the function of Prishtina only as a capital city. This has limited the efforts for development of the metropolitan concept within the administrative boundaries of Prishtina municipality, which, yet, depends on the will of the neighboring municipalities (Fushe Kosove, Obliq, Podujeva, Gracanica, Lipjan and Vushtrri) to associate strategically with Prishtina being the center of the concept. This study therefore finds that Prishtina as the Capital of Kosovo is less likely to generate a 
sustainable development for the country (as propagated in the Spatial Plan of Kosovo [8, pp. 126-127], if the concept limits the Capital within the boundaries of the municipality. Instead, the metropolitan concept should diversify the scope of potentials for Prishtina and should provide a new and different approach to urban development and management in a regional context, especially with neighboring countries of Albania and Macedonia.

The geographical dimension suggests that Prishtina, Tirana and Skopje can engage in cross-border projects without limiting themselves to the spatial development of their own territory. Instead, territorial approach would approach to corridors' and nodes' development, in which case physical boundaries would be substituted by flows of goods and people, hence creating the grounds for the networked cities in the regional triangle between Prishtina, Tirana and Skopje. This area would sustain the metropolitan criteria and would add value to the metropolitan concepts promoted by capital cities.

\subsection{Network of cities}

Network of cities is addressed in the Spatial Plan of Kosovo [8, p. 156], yet, the fact that the Law on Local Administration empowers municipalities in administrative terms, the concept of networks is in practice limited within the boundaries of municipalities. In other words, the functional network in Kosovo is the one of the city and villages bound to the territory of the respective municipality. The study finds that administrative borders are in many cases preventing the city from the potential spatial networking with the neighboring city. The sort of 'autonomy' granted to the municipalities through the decentralization process in Kosovo has in turn encapsulated cities. Although the potential and the mandate of cities to connect and network is guaranteed by law, no national strategy, guidance or grant is devised to support the alternative.

Drawing from this, the study suggests that the Capital city can create a model for a networking through the concept of the metropolitan capital, by networking with nearby cities of FusheKosove, Obliq, Podujeva, Gracanica, Lipjan and Vushtrri, which at the same time are part of the Prishtina region. This surrounding area made of these municipalities would infuse but at the same time would benefit from the concept of the regional corridors and nodes attached to the capital cities, as added value to the metropolitan concept.

\subsection{Regional cooperation}

Although widely encouraged through national strategies, regional cooperation remains still in the margins of the statutory actions in Kosovo. The Spatial Plan of Kosovo encourages thematic-territorial regions; yet, the Law on Spatial Planning regulates this activity only in the national and municipal level. Therefore, when it comes to spatial and urban planning and management in the regional level, no mandatory regulation or strategies are encouraged. The study finds that the regional component in the socio-spatial considerations facilitates the networking of cities that share common natural and cultural features of the territory [12, pp. 182-183], anticipating being crucial for the future development of Kosovo's urban portrait. Regions may not necessarily correspond to the divisions promoted in the Spatial Plan of Kosovo, which in any case 
should be considered and used as the basis for furthering the research in the field of spatial and urban development; the regions as envisioned by this study may spring from common characteristics and may exceed the limitations posed by municipal or national boundaries (Fig. 7).

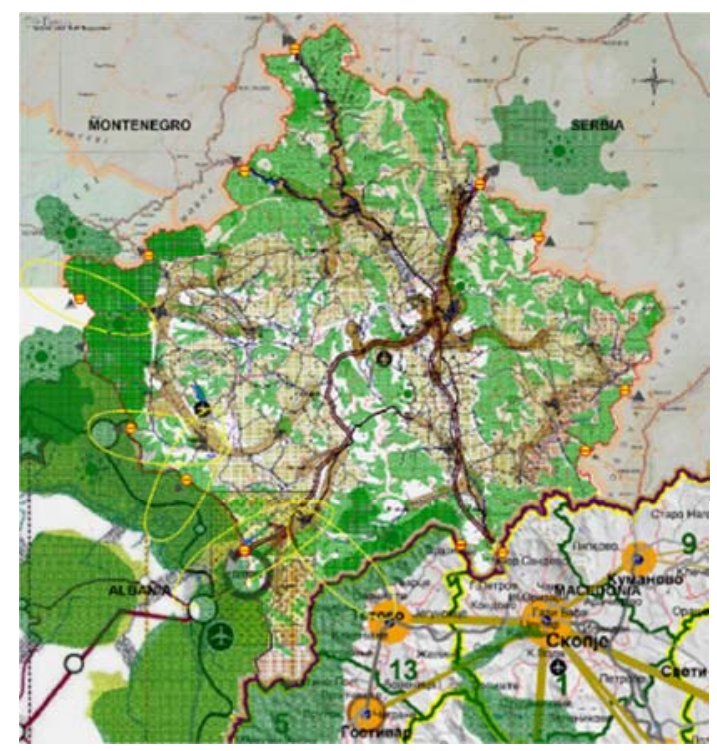

Fig. 7. Urban Potential of Kosovo (Source: Authors plot, Dukagjin Hasimja)

Promotion of natural and cultural landscapes regions in Kosovo may enrich the country's profile in one hand, while in the other hand, extension of the natural and cultural landscape approach beyond national borders and through the regional cooperation guarantees development in the regional context and by this, integration in the European political and economic context, includes development corridors and free economic areas [13, p. 123].

\section{Conclusions}

The future urban portrait of Kosovo cannot be understood outside the context of the Western Balkans and its future integration in the European socio-political, cultural and economic agenda. In order to achieve this goal, Kosovo should look at the potential of cross-border cooperation, initially with Albania and Macedonia. In this Endeavour, it is important to investigate components of the Kosovo urban profile that insert the most profound characteristics of the country's spatial potentials. Furthermore, the regional dimension of this kind of engagement would bring Kosovo closer to meeting requirements that spring from the EU integration process. There are three levels of cross-border cooperation that would guarantee a sustainable spatial, social and economic development of Kosovo in the context of the regional engagement, and by 
that, a new urban profile for the country: a new and enhanced concept of the metropolitan capital Prishtina, involving opening of development corridors with Skopje and Tirana; thus creation of nodes in which new spatial organization a new layer of networks of cities may emerge in the border zones but also in the suburbs of metropolitan areas.

In order to explore these options, future cross-border cooperation's should engage in joint projects that would identify possible natural landscape regions, which more often than not are subject to the common economic interests, especially in the bordering areas between Kosovo, Macedonia and Albania, cultural landscape regions, considering potential in Kosovo as well as potentials to connect thematically with those neighboring countries and beyond, due to the cultural uniqueness and diversity in the Balkans. All this opens up paths to possibly include and involve other Countries in the region, as Serbia and Montenegro in related studies in the future.

\section{References}

[1] Diener R., Herzog J., Meili M. de Meuron P., Schmid C. Switzerland - an urban portrait, ETH Studio Basel Contemporary City Institute, Birkhauser-Publishers for Architecture Basel, Boston, Berlin, 2002.

[2] Altić S. M. Povjesna geografija Kosova, Golden Marketing-Tehnička Knjiga, Zagreb, 2006.

[3] Berisha M. Archaeological guide of Kosovo, Ministry of Culture, Youth and Sport/ Archaeological Institute of Kosovo, Prishtina, 2012.

[4] Jashari-Kajtazi T. Architectural interpretation of the National and University Library in Prishtina; the influence in its surroundings, Pollack Periodica, Vol. 12, No. 1, 2017, pp. 171-180.

[5] Sylejmani M., Medvegy G., Beqiri L. Spatial layout of the functions in Kulla, Pollack Periodica, Vol. 12, No. 1, 2017, pp. 159-170.

[6] Lleshi Q. Kosova cities -Urban study, (in Albanian) 1977.

[7] Lefebvre H. The production of space, Blackwell Publishers Ltd, Oxford, 2000.

[8] Spatial plan of Kosovo 2010-2020+, Institute for Spatial Planning, Ministry of Environment and Spatial Planning, Prishtina, 2010.

[9] Ellin N. Postmodern urbanism, Princeton Architectural Press, NY, 1996.

[10] European Union/ Regional policy, Cities of tomorrow, Challenges, visions, ways forward, 2011, http://ec.europa.eu/regional_policy/sources/docgener/studies/pdf/citiesoftomorrow/ citiesoftomorrow_final.pdf, (last visited 15 September 2017).

[11] Bellini N., Hilpert U. Europe's changing geography: The impact of inter-regional networks, Routledge, New York, 2013.

[12] Taylor K., St Clair A., Mitchel N. Conserving cultural landscapes: Challenges and new directions, Routledge, New York, 2015.

[13] Aliaj B., Janku E., Allkja L., Dhamo S. Albania 2030 manifesto, A national spatial development vision, Shtypeshkronja Pegi, Tirana, 2014 